\title{
Neuroblastoma - Molecular Basis for Diagnosis and Staging System
}

\author{
Priscila Torres Babié, Ramón de J. Ropero Toirac, \\ Jesús de los Santos Renó and Samira Proveyer Derich \\ National Cancer Registry Department, \\ National Oncology and Radiobiology Institute, Havana, \\ National Cancer Control Unit of the Cuban Ministry of Public Health,
}

Cuba

\section{Introduction}

The origin of neuroblastoma was first described in Berlin, by Virchow in 1864, when he gave it the name "Glioma". In 1891, Marchand observed similarities between this tumor and the ganglia of the Sympathetic Nervous System in its developmental phase, and Wright demonstrated that the cellular type of this tumor was similar to the one observed in the embryonic stage of the medulla of the adrenal glands. The name Neuroblastoma was proposed by James Homer Wright in 1910, while Morgan observed microscopically an adrenal tumor with fibrillar characteristics. In 1914, Herxheimer, using Bielschowsky's method of silver staining, showed that the fibrillar structures were nerves fibers originating in the nerve cell proper, and not in the cells of the sheaths nerve as it has been noted in the case of a benign ganglioneuroma. Robertson indicated that any important series of these tumors of the neural crest were characterized by a variety of histological grades ranging from benign, with well differentiated cellular elements, to highly anaplastic forms. Rinscheid observed little fibrillar elements inside the tumor cells that were similar to those observed in normal neuroblasts. These findings were later confirmed by Murray and Stout in investigations done in vitro cultures of Neuroblastoma cells. Pepper described a supposed propensity for hepatic metastases (Pepper Metastases) in young children with Neuroblastoma, and Hutchison described a predilection for skeletal metastases(especially in the skull) from a primary Adrenal lesion in older children (Hutchinson metastases) In 1916, William Barlett, in Missouri, achieved the first successful tumor resection in a boy that survived for more than 15 years. Cushing and Worbach reported in 1922, in a 10 review, the progression of neuroblastoma to ganglioneuroblastoma. In 1928, Fill and Dresser used radiotherapy as treatment for neuroblastoma without success. Cytotoxic agents were introduced in 1940 without therapeutic results. In 1957, Mason published a report of a boy with neuroblastoma whose urine contained amine vasoconstrictors. This discovery contributed to the best understanding of neuroblastoma and its possible origin in the sympathetic nervous system [1].

He noted that it was common to have spontaneous regression of microscopic group of cells within the Neuroblastoma, called Neuroblastoma in Situ. According to Beckwith and Perrin, in 1963, this spontaneous regression occurred almost 40 times more frequently than the number of well defined true clinical cases. 
In 1965, James and colleagues (St Jude's Children Hospital), using combination chemotherapy appeared to have a small effect on the survival of these patients.

\section{Epidemiology}

The incidence of cancer children is analyzed according to the International Classification of Cancer in Childhood [2], which since its first edition has taken into account the classification of Birch and Marsden [3] which divides all the morphologies in twelve groups and forty seven diagnostic subgroups. The third edition of the International Classification of Cancer of Childhood is based on the third edition of the International Classification for Oncology (CIE-OR 3) [4], where all the morphological changes published in this classification have been upgraded. Neuroblastoma and Ganglioneuroblastoma are within group IVa of this classification.

Neuroblastoma (NB) is the most common neural crest derived extra cranial solid tumour of childhood and arises from sympathetic nervous tissue origins. It's the most common solid tumour in children younger than 5 years of age. It is the fourth most common paediatric malignancy, accounting for $7-10 \%$ of all childhood cancers and the most common cancer diagnosed during infancy with a median age at diagnosis of 18 months. Neuroblastoma is the fourth pediatric most frequent tumor and it burdens $6-10 \%$ of all cancers of the childhood. The highest incidence is during the first year of life, when about $1-2 \%$ of the cases are congenital tumors. It is often described as enigmatic and unpredictable disease and the incidence of spontaneous regressions is much greater than in any other human cancer $[5,6]$. The age range is wide, including children older than 5 years of age, in which only $10 \%$ of the cases are reported [5].

There are geographical differences in the incidence of Neuroblastoma. In the United States the frequency is reported to be 8-9: 1000000 children, while a screening of the population in Japan in the years 1984-2002 estimated the incidence to be approximately 180:1 0000000 [6]. In the United Kingdom only around 75 new cases have been diagnosed every year, in general, about 6 of each 100 cases of cancer in children younger than 15 years in that country [5,6,7]. In Germany, one of each 5000 children is affected, that is to say that in that country, every year, about 150 children are diagnosed with this disease. In Cuba, between the years 2000-2003, it represented 3,3\% of tumors in infants [8].

Neuroblastoma is more common in Caucasian children with a slight prevalence in boys. The ratio of male to female is 1.3: 1 [12].

It is difficult to find population data about the mortality for this tumor because the data on mortality, published by the statistical registrations at world level, are based on the anatomical localization of the tumor and not related to its morphology, This makes it difficult to obtain accurate data to evaluate the mortality rate of Neuroblastoma, due to its propensity to present itself in multiple anatomical locations. Therefore we suggest that the information about infant mortality be reported by diagnostic groups as well as the incidence.

\section{Cytogenetic and molecular characteristics}

According to Knudson and Strong (1972), 20\% of All neuroblastomas are inherited through an autosomal dominant pattern, whether solitary, bilateral or multifocal tumors. It can have 
several abnormalities in the karyotype, but the deletion of the short arm of chromosome number 1 is found in $70-80 \%$ of all patients with neuroblastoma14. The malignant transformation and persistence of the state of differentiated cells of the neural crest can be the result of the failure of these cells to respond to the normal signals that are responsible for the normal morphological differentiation. The factors involved in the cascade of events are not well known, but probably involve one or more lines of the binding receptor. One of the more popular and well studied lines is the Nerve Growth Factor (NGF) and its receptor (NGFR).

Tumours with N-myc amplification or loss of heterozygosis for chromosome 1p generally have a poor prognosis. NB cells vary in relation to their differentiation stage, with aggressive NB tumors deriving from more immature NB cells. These NB tumors may be present as phenotypically distinct groups of NB cell types (i.e.neuroblastic, neuroendocrine) organized in lobular structures with a central necrotic/hypoxic zone. Recent evidence has demonstrated that NB cells growing in these necrotic/hypoxic zones undergo a gene expression switch involving decreased expression of neuronal/neuroendocrine marker genes, but induced gene expression of neural crest sympathetic progenitor markers. These data, indicating that hypoxia causes dedifferentiation of NB cells to proliferative immature neuroblast-like cells, suggest potential activation of epithelial mesenchyme transition mechanisms (EMT). Although EMTs occur during critical phases of embryonic development in many animal species, it is now well recognized that EMT is a potential mechanism for cancer progression. However, the activation of these events in hypoxic NB cells remains largely undetermined [16].

Recently, continuous lines of human NB cells in culture have established that enzyme activities associated with neurotransmitter biosynthesis have been detected in approximately 10 independently derived cell lines [10]. The unresolved questions are whether and to what extent an individual tumour consists of a mixture of functionally differing neuronal phenotypes and whether and to what extent a single NB cell may have the potential for synthesis of more than one transmitter. Results of several combined clinical and biochemical studies suggest that the cells established in culture reflect the characteristics of the tumour from which they were derived. Although karyotype analysis of the human cell lines has revealed the presence of consistent marker chromosomes suggestive of clonal origin of individual neuroblastomas, the possibility of functional diversity and multipotentiality of the tumor cells in vivo cannot be explored by studying the tumour cell population as a whole. To obtain evidence regarding functional properties as well as phenotypic stability of human NB cells, it was isolated clones from the NB lines SK-N-SH and SK-N-MC and began their characterization. These 2 parental lines were compared to a hitherto uncharacterized set of NB lines, SK-N-BE(1) and SK-N-BE(2), isolated at different times from the same patient and possessing several biological and biochemical features in common [17].

Genetic studies have an important role in formulating the prognosis in children with neuroblastoma, because certain acquired genetic abnormalities in the tumour cells correlate closely with the clinical outcome. Established indicators of the aggressiveness of the tumour and poor outcome include the deletion of the short arm of chromosome 1 (1p), the amplification of the $\mathrm{N}$-myc gene, and near diploidy or near tetraploidy. Conversely, the presence of $1 \mathrm{p}$, single copies of $\mathrm{N}$-myc, near triploidy, and expression of the TRK gene are significantly associated with a favorable prognosis. Recent methods revealed that the gain of material from chromosome 17 is the most frequent genetic abnormality of NB cells, with an incidence ranging from 63 to 83 percent. This gain may consist of an entire chromosome 17 
(e.g., tetrasomy17 in a triploid tumour) or of only the distal segment of the long arm, 17q21qter. Such a partial gain is strongly associated with risk factors: age of more than one year, presence of advanced disease, deletion of $1 \mathrm{p}$, amplification of the $\mathrm{N}$-myc gene, and unfavourable ploidy. The principal mechanism underlying partial gain of $17 \mathrm{q}$ is an unbalanced translocation, with a variety of partner chromosomes. The segment on the partner chromosome distal to the breakpoint is lost, and a segment of $17 \mathrm{q}$ translocates to that site [18].

It is also found on virtually all unipotent and multipotent colony-forming cells, on blast colony-forming cells, and on precursors of colony-forming cells detectable in long-term marrow culture. This antigen has been identified by antibodies MY-10, BI-3C5, ICH3, and 12-8. Previous work has demonstrated that isolated autologous CD34+ marrow cells can engraft lethally irradiated baboon, It has been observed that the CD34 antigen is not detected on tumour cells from patients with most solid tumors including breast cancer and neuroblastoma. In viitro studies have demonstrated that immunoadsorption with antibody 12-8 can be used to separate normal marrow progenitors from tumor cells. There is considerable evidence suggesting that ATP functions as an extracellular signaling molecule in neural and nonneural mammalian tissues. In central and peripheral synapses, ATP mediates fast excitatory neurotransmission. In the autonomic nervous system, ATP is a major purinergic cotransmitter that is often colocalized in secretory vesicles with norepinephrine or acetylcholine. In the vascular system, aggregating platelets secrete ATP and ADP, which stimulate the release of nitric oxide and other vasodilators from the endothelium. In the immune system, ATP modulates macrophage phagocytosis and mast cell degranulation. In the human airway epithelium, ATP stimulates trans-epithelial ion transport, an effect that may underlie the therapeutic effect of ATP and UTP in the treatment of cystic fibrosis-related lung disease. It has been postulated that these responses to extracellular ATP are mediated by specific plasma membrane receptors, called P2 purinergic receptors. Based on agonist selectivity and signalling properties, five subclasses of P2 receptor have been tentatively defined: three subclasses of receptors (P2T, P2U, and P2y) that are believed to signal through $\mathrm{G}$ proteins, one subclass (P2X) that is believed to be a ligand-gated cation channel, and one subclass $(\mathrm{P} 2 \mathrm{z})$ that is present on mast cells, macrophages, and fibroblasts, but whose signalling mechanism is less well understood. G protein-coupled P2 receptors are found in numerous cultured cell lines, where they have been shown to activate signal transduction systems that involve the breakdown of membrane phospholipids and the elevation of cytoplasmic free Ca2+. Ionotropic P2X receptors carry $\mathrm{Na}+, \mathrm{K}+$, and $\mathrm{Ca} 2+$ currents and appear to be predominantly expressed in neural and neuromuscular tissues. A more complete characterization of this putative family of P2 purinergic receptors has been hampered by the complete lack of specific P2 receptor antagonists, radioligands, and cloned receptor cDNAs. To circumvent this difficulty, we have used a Xenopus laevis oocyte expression cloning strategy to isolate a cDNA encoding a functional P2U receptor from NG108-15 neuroblastoma x glioma hybrid cells [19].

Of considerable interest in connection of herpes simplex virus 1 (HSV-1) with this disease are the genes that confer the capacity to replicate in the central nervous system (CNS) tissues. The y134.5 gene is located in the inverted repeats flanking the long component of viral DNA and therefore the gene is present in two copies per genome Its location is consistent with previous reports showing that a locus that affected the capacity of the virus to multiply in the CNS tissues mapped at the right end of the long component of HSV DNA in the prototype arrangement [20]. 


\section{Forms of clinical presentation}

Neuroblastoma has been called the great imitator due to its varied clinical presentations, related to the anatomical distribution of the Sympathetic Nervous System, location of the primary tumor, metastasis and metabolic byproduct of the tumor.

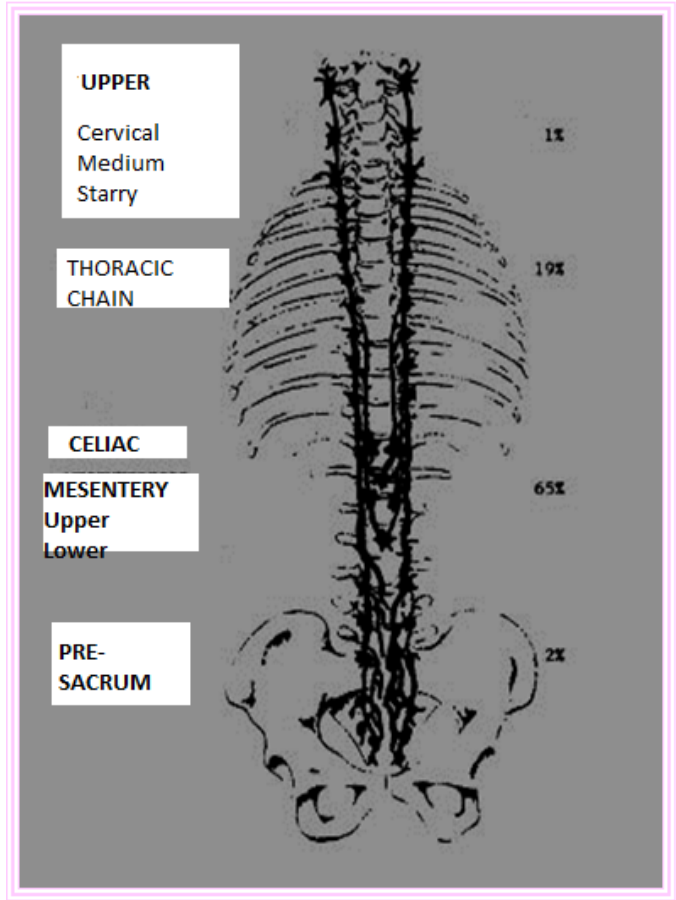

From: Bowman LC et to 1994 J. Clin Oncol 9: 1599 - 1608

Fig. 1. Anatomical distribution of the sympathetic nervous system and frequency of localization of Neuroblastoma according to regions.

Seventy five percent of primary Neuroblastoma occur in the abdomen, and most of these happen in the Adrenal (50\%) Glands. As a result, most of the children affected complain of abdominal discomfort, such as fullness and, or abdominal distension. The most common symptoms are related to pain in the abdominal mass and the bones, secondary to metastatic neuroblastoma. The complaints of fatigue, pain in bones, and changes in intestinal habits can contribute to the exact diagnosis. The physical findings could include hepatomegaly, hypopigmented subcutaneous nodules, big, firm irregular abdominal mass.

Typically children with localized disease are asymptomatic, while \{the\} children with disseminated neuroblastoma are generally sick and they can have systemic manifestations, including fever of unknown origin, marked weight loss, anorexia, diarrhea, growth problems, general malaise, irritability and bone pain, difficulty walking, subcutaneous nodules, hepatomegaly, adenopathy, asthenia, paleness, proptosis, periorbital hematoma, hypertension, paraparesis, paraplegia, cerebellar ataxia $[9,10]$. 
At the time of diagnosis, the site of the neuroblastoma is predictable depending on the patient's age. Infants often present with compression of the Sympathetic Ganglia in the thoracic region which could manifest, for example, as a Horner's Syndrome (myosis, anhydrosis, and palpebral ptosis palpebral) or as a Superior Vena Cava Syndrome. Older children typically present with abdominal pain because as it was mentioned previously, more than \{of\} $40 \%$ of neuroblastomas originate in the adrenals. More than $50 \%$ of the patients who present with neuroblastomas have metastatic disease. The most frequent sites of involvement are, the bone marrow, bones, liver, lymph nodes and skin [10].

The appearance of other syndromes also related to neuroblastoma is not surprising; Pepper's Syndrome, for example, occurs in infants with liver metastasis which causes respiratory insufficiency. Described by William Pepper in 1901, it was identified as a primary localized tumor with metastatic disease limited to the skin, liver, and bone marrow; in children it has been associated with neuroblastoma stage IVs. This syndrome is the only entity that only occurs in children younger than 1 year of age. It generally confers a better prognosis when spontaneous regression is associated with this entity; however some children with stage IVs can die from massive hepatomegaly, respiratoty failure, and generalized sepsis. Hepatoblastoma should be considered in the differential diagnosis $[9,10]$.

Babies called "Blueberry muffin" are infants whose neuroblastoma has randomly metastasized to subcutaneous areas. These nodules become intensely red when first touched followed by blanching, lasting several minutes. This response is probably secondary to the discharge of vasoconstrictors derived from metabolic byproduct of the tumor. These nodules can be the diagnosis of neuroblastoma [11].

Extensive metastases of neuroblastoma to bone can produce bone pain and as consequence, limping and pathological fractures. Neuroblastoma involving the paravertebral ganglia can extend through nerve foramina, and cause spinal cord compression with subsequent paralysis. Infrequently, neuroblastoma can metastasize to the retrobulbar region, progressing quickly to a unilateral proptosis without pain, to periorbital edema, and to ecchymosis of the superior part of the eye, characterized as the syndrome of Hutchinson. Those signs can be mistaken for trauma in a child [23]. This syndrome can also be characterized by preauricular, ipsilateral sub maxillary and upper cervical adenopathy, as well as metastasis to lymph nodes of the retroperitoneum, mediastinum and supraclavicular region.

Most neuroblastomas produce catecholamine like substances as metabolic byproducts that are responsible for some of the most interesting manifestations observed in children with this disease. For example, Kerner-Morrison's syndrome causes secretory refractory diarrhea, producing hypovolemia, hypokalemia, and prostration. This is secondary to the vasoactive intestinal peptide (VIP) secreted by the tumor. This syndrome is usually associated with ganglioneuroblastoma or ganglioneuroma [11].

The diagnosis of neuroblastoma requires the participation of pathologists who are well familiarized with children's tumors. Some of the cells cannot be differentiated from small, round, blue cells found in other childhood tumors (such as lymphomas, primitive neuroectodermal tumors and rhabdomyosarcoma) by simple light microscopy. The evidence necessary to make the differentiation of neurosympathetic origin should be demonstrated by immunohistochemistry, electron microscopy, elevated levels of serum 
catecholamines (dopamine, noradrenaline) or catecholamine metabolites in the urine, vanillylmandelic acid (VMA) or homovanillyc acid (HVA) [10].

The minimum criteria required to determine a diagnosis definition of Neuroblastoma has been recently established by an international group of experts and the corresponding participants. These are unequivocal pathological diagnosis or the unequivocal presence of scyncytium cells in the bone marrow, as mentioned before [10, 32].

The staging and monitoring of disease in patients with NB are major areas of application for diagnostic imaging methods. Thus, diagnostic studies that enable accurate tumour staging should help in treatment planning and reduce unnecessary surgery. The current staging evaluation of patients with $\mathrm{NB}$ consists of computed tomography (CT) or magnetic resonance (MR) imaging of the primary tumour, a skeletal survey and either bone scintigraphy or metaiodobenzylguanidine scintigraphy for skeletal metastases, and bone marrow aspiration and biopsy for marrow disease. CT has a reported accuracy of about $80 \%$ in tumor staging; when CT is complemented with scintigraphy or bone marrow aspiration, the accuracy has been reported to increase to $97 \%$ (15). MR imaging has also yielded high sensitivities (85\%-100\%) in the detection of abdominal disease and distant metastases [33].

There are organized systems to classify Neuroblastomas. Historically, each organized system has represented a temporary improvement in the understanding of this tumor. However, the existence of so many systems has not only confused the literature, but it has also complicated the comparison of studies among the different institutions27. A standard of clinical criteria exists for diagnosis, staging and response to therapy known as The International Neuroblastoma Staging System (INSS), determining the necessity to obtain biological (histopathological and genetic) data to create therapeutic new groups internationally. In 1984, Shimada classified the neuroblastomas correlating their histopathological features with their clinical behavior. With this purpose, Shimada divided neuroblastomas into favorable and unfavorable categories, depending on the grade of differentiation of the neuroblasts, quantity of Schwannian spindle cell stroma, the index of mitosis- karyorrhexis, and the age at diagnosis [12].

It has been observed that there are two types of Neuroblastoma with very different prognosis, which do not differ either biochemically or histologically, but from the genetic molecular aspect which allows the determination of unfavorable risk factors Amplified Nmyc, deletion of 1p, DNA euploidy, CD44 and N-level. These risk factors are rarely found in children younger than 1 year of age, but they are present in one third of Stages III and IV Neuroblastoma in children older than 1 year of age [13].

At this moment $\mathrm{N}$-myc is considered to be the best genetic molecular parameter to define risk groups. For many years the patient's age and the stage of the disease at the moment of diagnosis were the two variables most significant in predicting prognosis in neuroblastoma. Evans found that the nursing infants younger than 1 year old with stages I, II and IV-s had significantly better prognosis. Patients older than 1 year of age and those with more advanced stages, that is to say, III and IV, had worse prognosis. The worst survival prognosis is observed in children older than 1 year of age, in stage IV and with cortical bone metastasis. The site of the primary tumor was also considered a predictor of survival according to some investigators. The patients with tumors in neck, pelvis and mediastinum have better prognosis when compared with those that present with tumors in the retroperitoneal space (paraspinal or Adrenal Glands) $[9,13]$. 


\begin{tabular}{|c|c|c|}
\hline CCG or Evans System & POG* System & INNS** System \\
\hline $\begin{array}{l}\text { Stage I } \\
\text { Tumor confined to the } \\
\text { organ or structure of origin }\end{array}$ & \begin{tabular}{|l|} 
Stage A \\
Complete microscopic \\
resection of primary tumor \\
with or without residual \\
microscopy. Intracavitary \\
lymph nodes not adhered to \\
the primary tumor and \\
histologically free of tumor. \\
Positive lymph nodes \\
adhered to the surface or \\
inside the tumor.
\end{tabular} & $\begin{array}{l}\text { Stage } 1 \\
\text { Localized tumor, microscopic } \\
\text { complete resection, with or without } \\
\text { microscopic residual disease. } \\
\text { Ipsilateral lymph nodes negatives for } \\
\text { microscopic tumor. Positive lymph } \\
\text { nodes adhered to the resected tumor }\end{array}$ \\
\hline $\begin{array}{l}\text { Stage II } \\
\text { Tumor that extends }\{\text { for }\} \text { by } \\
\text { continuity beyond the } \\
\text { original organ, but it } \\
\text { doesn't cross the midline. } \\
\text { Positive regional ipsilateral } \\
\text { lymph nodes. }\end{array}$ & $\begin{array}{l}\text { Stage B } \\
\text { Microscopic incomplete } \\
\text { resection of the primary } \\
\text { tumor. Lymph nodes and } \\
\text { liver similar to stage A. }\end{array}$ & $\begin{array}{l}\text { Stage 2 A } \\
\text { Localized tumor, with microscopic } \\
\text { incomplete resection. Representative } \\
\text { ipsilateral lymph nodes not adhered, } \\
\text { negatives for microscopic tumor. } \\
\text { Stage 2B } \\
\text { Localized tumor, microscopic complete } \\
\text { or incomplete resection, ipsilateral } \\
\text { lymph nodes or adhered positive } \\
\text { nodes Contralateral lymph nodes } \\
\text { negative for microscopic tumor. }\end{array}$ \\
\hline \begin{tabular}{|l|} 
Stage III \\
Tumor that extends \{for $\}$ by \\
continuity beyond the \\
midline, positive bilateral \\
lymph nodes.
\end{tabular} & \begin{tabular}{|l|} 
Stage C \\
Complete or incomplete \\
resection of the primary \\
tumor. Lymph nodes not \\
adhered to the primary \\
tumor, histologically positive \\
for tumor, liver similar to the \\
stage A
\end{tabular} & $\begin{array}{l}\text { Stage } 3 \\
\text { Unilateral unresectable tumor that } \\
\text { crosses the midline, with or without } \\
\text { positive regional lymph nodes; or } \\
\text { unilateral tumor that is localized, with } \\
\text { positive regional contralateral lymph } \\
\text { nodes; or tumor in the midline that has } \\
\text { extended bilaterally by continuity or } \\
\text { by involving lymph nodes. }\end{array}$ \\
\hline $\begin{array}{l}\text { Stage IV } \\
\text { Metastasis to Bone, bone } \\
\text { marrow, soft tissue and } \\
\text { distant lymph nodes. }\end{array}$ & $\begin{array}{l}\text { Stage D } \\
\text { Disease spreading beyond } \\
\text { Intracavitary lymph nodes }\end{array}$ & $\begin{array}{l}\text { Stage } 4 \\
\text { Any primary tumor with distant } \\
\text { metastasis to lymph nodes, bone, liver, } \\
\text { skin, bone marrow or other organ } \\
\text { (except the defined by Stage IVs). }\end{array}$ \\
\hline \begin{tabular}{|l|} 
Stage IV-S \\
Defined as Stages I or II, \\
except for the presence of \\
distant disease confined to \\
skin, liver or bone marrow \\
(without bone metastases) \\
or both.
\end{tabular} & $\begin{array}{l}\text { Stage D-S } \\
\text { Nursing children younger } \\
\text { than } 1 \text { year-old, with Stage } \\
\text { IVs disease (CCG Staging }\end{array}$ & $\begin{array}{l}\text { Stage } 4 \mathrm{~S} \\
\text { Localized primary tumor (as define in } \\
\text { the Stage 2A or 2B, with limited } \\
\text { spread to liver, skin, bone marrow). } \\
\text { Nursing infants younger than one } \\
\text { year old. }\end{array}$ \\
\hline
\end{tabular}

Classification by Shimada and Jhosi (1992 and 1999) establishes a prognostic classification based on histological features, the patient's age, presence or absence of stroma, the grade of differentiation and the index of Mitosis-Karyorrhesis (MKI).

Table 1. Neuroblastoma Staging System. Comparison of the three systems 


\begin{tabular}{|l|l|l|}
\hline Poor stroma & $\begin{array}{l}\text { Favourable histology } \\
\text { Well differentiated } \\
\text { Intermediate }\end{array}$ & $\begin{array}{l}\text { Unfavourable histology } \\
\text { Nodular }\end{array}$ \\
\hline Poor stroma & MKI $<200 / 5000$ & MKI $<100 / 5000$ \\
\hline Age $<18 \mathrm{~m}$ & MKI $>100 / 5000$ & MKI $<100 / 5000$ \\
\hline Age $18-60 \mathrm{~m}$ & Differentiated & Undifferentiated \\
\hline Age $<5$ years old & None & All \\
\hline
\end{tabular}

FROM: Grosfeld JL et to 2002 Cir. Pediatr 12: 1345-46

Table 2.

\section{Diagnosis}

To carry out the diagnosis of this disease, it is necessary to keep it in mind, to take into account the epidemiological aspects described before, the signs and symptoms described in the forms of clinical presentation, added together to the study of the catecholamines, the blood chemistry result: complete hemogram with differential, glycaemia, urea, creatinine, study of \{the\} hepatic (TGP, TGO, alkaline phosphatase) function, radiological study of the thorax including CAT Scan and MRI. If needed, abdominal ultrasound, bone scan included the bone gammagraphy, bone marrow examination, histological study (included immunohistochemistry) of a biopsy of the lesion.

\section{Tyrosine}

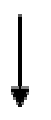

DOPA
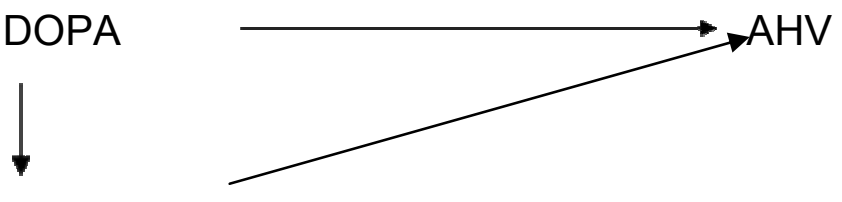

Dopamine

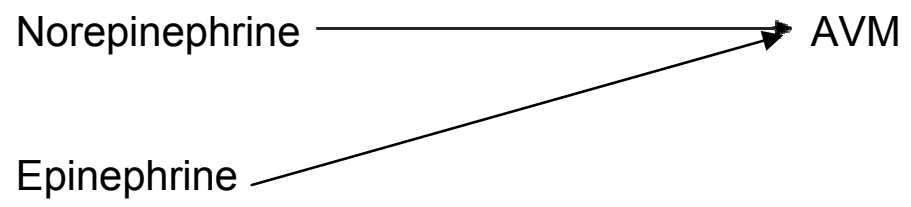

The following studies are being referred to due to their significant importance. [10]: 
- The examination of the bone marrow aspirate is characterized by the presence of malignant cells, that can present a diffuse pattern or, in its characteristic way of rosettes (Homer-Wright rossetes). They appear in nests or islands of atypical cells separated by septa, disseminated among the normal cells of the bone marrow.

- Study of levels of Catecholamines in blood and in urine. With sensitive technique, in more than $95 \%$ of these tumors elevated urinary metabolites can be detected: homovanilic acid (AHV) and the\} vanillylmandelic acid (AVM).

Catecholamine is the generic name of the amines derived from catechol or 1,2-bencenodiol; being the most important epinephrine, norepinephrine and their precursor, DOPA (dihydrophenylalanine), of sympaticomimetic action. In the following figure it is show in a simplified manner [10]:

- By means of a biopsy it is possible to obtain the two histological varieties of this tumor: Ganglioneuroblastoma (morphological code 9490/3) and Neuroblastoma (morphological code 9500/3)

In half of the cases, metastasis is already present at the time of diagnosis, especially in regional organs and distant lymph nodes, in the bone marrow, bone, liver, skin, and rarely in the Central Nervous System.

\section{Differential diagnosis}

Fundamentally with: non Hodgkin lymphomas, Ewing sarcoma and rhabdomyosarcoma $[10,14]$.

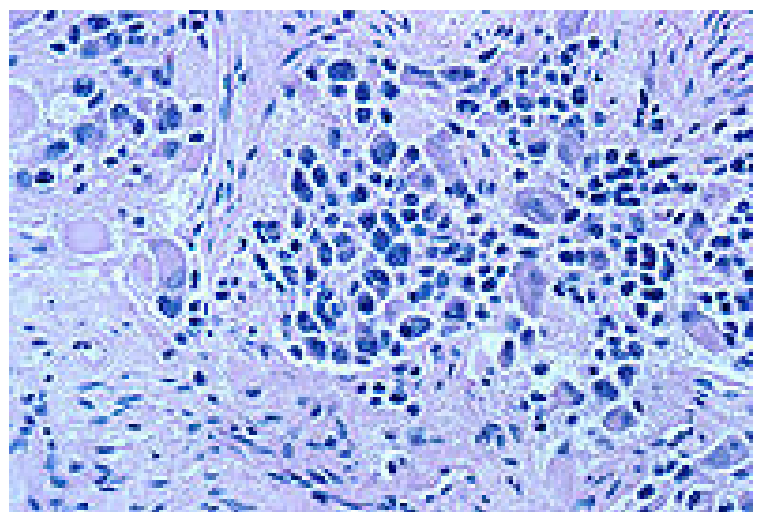

Fig. 2. Cells of a nerve ganglion with neuroblastoma.

\section{Prognostic factors}

Certain biological variables have been identified that affect the prognosis of children with neuroblastoma. The specific examples include the aneuploidia of the DNA in the tumor and the amplification of the oncogene N-myc. The amplification of N-myc happens in $20 \%$ of the primary neuroblastoma and it is associated with a neuroblastoma subset that has a high metastatic potential and a POOR prognosis. It is thought that N-myc contributes to the 
aggressive behavior of neuroblastoma. However, the precise role of non-amplified N-myc in tumors is unknown $[9,15,16]$.

The hyperdiploidity of the DNA in tumors is associated with a favorable prognosis. The amplification of $\mathrm{N}$-myc is associated with a POOR prognosis in children older than 1 year of age, but not in children younger than 1 year of age. The amplification of N-myc is associated with the deletion of the short arm of chromosome $1 \mathrm{p}$ and a gain on the long arm of the chromosome 1755. In neuroblastoma, areas consistently showing heterogenecity of the chromosome $(\mathrm{LOH})$ include bands of the chromosomes 1p36, 11q23, and 14Q23qter. In 2000, Maris et al. informed the Children's Cancer Group (CCG) that the deletion of the 1p predicted a lower survival independently, but not the overall survival. The clinical relevance of $14 \mathrm{q} \mathrm{LOH}$ is uncertain at this time. There are other prognostic variables such as the level of ferritin in serum, of neuron-specific enolase (NSE), and the nutritional status of the patient $[17,18]$.

Different prognostic factors have been described in Neuroblastoma, but most of the reviewed authors classify them as favorable factors and unfavorable factors $[10,19,20]$.

Favorable factors:

1. Early clinical stages (I, II, IVS)

2. Location: thorax, pelvis, and neck

3. Age: younger than one year of age

4. Favorable histological pattern of Shimada:

- STROMA rich in cells of Schwann, diffuse

- Neuroblasts with nuclear and cytoplasmic differentiation toward node cells.

- MKI Index (mitosis / karioresis) related to age: younger than 18 months: MKI < 200/5000; from 18 to 24 months < 100/50.000 and from 2 to 5 years not

5. Normal homovanillic acid (HVA) in urine.

6. Normal serum levels of ferritin and neuron-specific enolase.

7. Negative intestinal vasoactive peptide.

8. Good Nutritional State

9. DNA aneuploidy.

10. Oncogene $\mathrm{N}-\mathrm{myc}<10$ amplifications

11. Absence of metastasis.

Other factors associated separately, to a favorable evolution and inversely related to the amplification of the gene $\mathrm{N}-$ myc they are:

- The expression of the gene that codes the receptor of the factor of High Neural Affinity named proto oncogene TRK-TO

- The expression of the receptor Low Neural Affinity (LNGFR)

- $\quad$ H-ras p21 oncogene expression

Unfavorable factors:

1. Stage: III and IV

2. Location: retroperitoneum

3. Age: older than 1 year old

4. Histologic pattern: undifferentiated neuroblastoma 
5. Increase in the index homovanillic acid/ vanillylmandelic acid.

6. Increase in serum level of ferritin, neuron-specific enolase and LDH.

7. Increase of intestinal vasoactive peptide.

8. Malnutrition.

9. DNA diploidy

10. Oncogene $\mathrm{N}$-myc with $>10$ amplifications

11. The loss of expression of the glycoprotein CD44 on the surface of the tumor.

12. Metastasis to regional lymph nodes.

13. Increased levels of p-glycoprotein after chemotherapy

14. The activation of gelatinase $A$ is related with high expression of MT-MMP-1 (membrane-type matrix metalloproteinase-1) in neuroblastoma cells, and in turn it is related with advanced stages and with worse outcome.

NOTE: p-glycoprotein is the protein produced by the gene that code for drug multiresistance.

Contrary to what has happened \{to\} with other embryonic tumors in children, in which the combined treatment of the different therapeutic modalities of the cancer has achieved a considerable increase in survival, the prognosis of neuroblastoma continues to be uncertain.

\section{Treatment}

The treatment of NB is determined by the stage of the tumor at time of diagnosis. Disease that is regionally limited is potentially resectable, while disease that is locally extensive or disseminated is usually not resectable.

In 1988, the Pediatric Oncology Group (POG) carried out a study that revealed that $89 \%$ of patient with localized neuroblastoma that were treated by surgical resection had a survival of only 2 years. Additionally, chemotherapy seemed to have offered no advantage residual disease was present in these patients 34 . Therefore, for patients with favorable stage, surgery is the main form of therapy. The most important goals of surgery are: to determine an exact diagnosis, to excise completely the entire primary tumor, to provide the exact surgical findings, the adjuvant therapy in delayed primary surgery, and to remove residual disease in second look surgery[21].

Since surgery is only done in early stages of neuroblastoma (stages I and II) multi agent chemotherapy is the conventional therapy for patients in the most advanced stages of neuroblastoma. In children younger than one year of age with disseminated neuroblastoma, favorable results have been obtained with the combination of chemotherapy and surgery. In contrast, children older than 1 year of age with neuroblastoma in advanced stage have a very low survival rate, despite intensive multimodality therapy [36]. Due to these observations, in Japan, during the 1980's it was proclaimed that an aggressive exploration in children younger than 6 months with catecholamines in the urine could uncover earlier neuroblastoma which could result in better outcome. In Europe and North Americ controlled clinical tests were carried out in the affected population and when comparing results with those of the Japanese study, no benefits were found with this investigation [22].

In spite of these confusing studies, symptomatic treatments are available for patients with neuroblastoma. The Adrenocortical Hormone (ACTH) is thought to be quite effective, although some patients are resistant. Plasmapheresis and gamma globulin have been used 
in the treatment of selected patients with neuroblastoma; however, it is thought that treatment with chemotherapeutic agents produce better neurological results [23].

The common chemotherapeutic agents used to treat Neuroblastoma include cisplatin, doxorubicin, cyclophosphamide, and the epipodophyllotoxins (teniposide and etoposide). The protocols with combination of narcotics have used strategies that take advantage of drug synergism, mechanism of toxicity, and variety of adverse effects. Despite the different drug combinations, the rate of cure has not been significantly affected. The long term survival of patient with metastatic neuroblastoma is low. It is believed that this is due to the presence of a large number of non-proliferating cells in the tumor. However, in neuroblastoma treated with chemotherapeutic agents a reduction in the size of the primary tumor, occasional sterilization of the bone marrow, and, rarely, transformation of the neuroblastoma into a benign ganglioneuroma have been observed [24].

The current tendencies for the use of chemotherapy in the treatment of neuroblastoma include: dose-intensive chemotherapy followed by surgical excision of residual disease myeloablative therapy by combination of chemotherapeutic agents, followed by Autologous Bone Marrow Transplantationand biological responder modifiers, to bring about differentiation of the tumor and to reduce the degree of bone marrow infiltration [40]. The multimodal therapeutic protocols outlined by POG are the norm of care for children diagnosed with neuroblastoma.

Topotecan, an inhibitor of the topoisomerasa I, alone or in combination with Cyclophosphamide, has shown to have activity against recurrent neuroblastoma. This information has recently prompted the Children's Oncology Group to design a study to prove the clinical effectiveness of incorporating Topotecan in an intensive induction régimen for patients with high-risk neuroblastoma.

Retinoic acid (RA), a biologically active form of vitamin A, plays a central role as a signaling molecule in the early stages of embryonic development and the generation of multiple organs and systems, including the Nervous System [59]. In vitro culture it has been demonstrated a decrease in the regulation of the expression of the $\mathrm{N}$-myc messenger RNA which obstructs the proliferation of tumor cells. These observations taken to clinical trials demonstrated the efficacy of 13-cis RA in children with neuroblastoma in relapse. The results of phase I and II trials didn't show benefits in patients with high tumor load; however in patient with minimal disease, phase III randomized trials involving, 13-cis RA produced an improved rate of survival from $20 \%-40 \%$ in patient with high risk neuroblastoma [24].

Indirect immunotherapy has been evaluated as part of multimodal treatment of microscopic resistant neuroblastoma. Diasilganglioside (GD2) is an excellent target for immunotherapy because this antigen is overexpressed in the majority of human neuroblastoma. The response rate is reinforced for those that have used cytosine combinations along with antiGD2 antibodies, increasing the antibody dependent cellular cytotoxicity (ADCC). Other immunotherapies like cytotoxic $\mathrm{T}$ lymphocytes, modified dendritic cells, fusion protein $\mathrm{Hu}$ 14.18-IL2 (immnunocytokine), GM-CSF, and interleukine-2 (IL-2) have shown promising results against neuroblastoma.

The clinical trials in Europe and North America are delineating the effectiveness of the radio-tagged methyliodobenzylguanidine (MIBG) with I-131 with or without combination 
myelobastic chemotherapy, followed by rescue with autologous stem cells. The optimal doses, schedules, and best timing for MIBG therapy are the goals of these clinical trials [25].

On the other hand, the therapy with antiangiogenesis has more than a theoretical role in the treatment of neuroblastoma. In fact, the preclinical studies have demonstrated that these agents inhibit the growth of neuroblastoma in vivo, mainly in minimal residual disease. Phase I protocols that test inhibitors of angiogenesis allow the determination if a very vascular neuroblastoma responds to these agents.

In vitro cultures have demonstrated that neuroblastoma is radiosensitive, but the clinical trials carried out have been unclear and inconclusive. As a primary modality of treatment, radiation therapy still has a limited role. In metastatic regional lymph nodes sequential chemotherapy with cyclophosphamide can be used.

Intensive multimodal treatment of patient with neuroblastoma has shown an increase in survival rate. However, the risk of therapy related delayed manifestations must be taken into consideration because of adverse, devastating effects. Survivors should be closely followed and supervised by multidisciplinary Centers to detect and document any long term sequelae. The Oncological Pediatric (GOP) Group recently developed a classification system named Neuroblastoma Risk Stratification System (NRSS). This new classification includes biological and clinical characteristics to predict behavior, similar to the Shimada Index and it is also used with the purpose of stratifying the treatment. The patients are classified in the categories of low, intermediate or high-risk according with the age at the diagnosis, the staging according to INSS, the histopathological features, the state of amplified N-myc and the DNA index.

\section{Protocols of treatments}

Low Risk Disease (Protocol I)

\begin{tabular}{|l|l|l|}
\hline Cyclophosphamide & $400 \mathrm{mg} / \mathrm{m}^{2} / \mathrm{BS} / \mathrm{IV}$ & Day 1 \\
\hline Vincristine & $1.5 \mathrm{mg} / \mathrm{m}^{2} / \mathrm{BS} / \mathrm{IV}$ & Day 1 \\
\hline Adriamycin & $30 \mathrm{mg} / \mathrm{m}^{2} / \mathrm{BS} / \mathrm{IV}$ & Day 8 \\
\hline
\end{tabular}

4 weeks rest.

Total number of cycles: 6

Intermediate risk (Protocol II)

\begin{tabular}{|l|l|l|}
\hline Block $A^{*}$ & Dose & Day \\
\hline Cyclophosphamide & $1500 \mathrm{mg} / \mathrm{m}^{2} /$ BS/ IV & Day 1 \\
\hline Vincristine & $1 \mathrm{mg} / \mathrm{m}^{2} /$ BS/ IV & Day 1 and 2 \\
\hline Rest 3 weeks & \multicolumn{2}{|l|}{} \\
\hline Block B & $120 \mathrm{mg} / \mathrm{m}^{2} /$ BS / IV & Day 1 \\
\hline Cisplatin & $100 \mathrm{mg} / \mathrm{m}^{2} /$ BS /IV & Day 1,2 and 3 \\
\hline Etoposide & \\
\hline $\begin{array}{l}\text { Rest 3 weeks } \\
\text { Total of cycle: } 6\end{array}$
\end{tabular}

*In stage III, the use of radiotherapy is recommended to help in the reduction of the primary tumor volume during the weeks of the first cycle of Block A plus 2 more weeks. 
Considerations for surgery are taken as soon as the cytoreduction of the tumor is achieved. It is recommended to start evaluation for surgery from the third cycle.

High risk disease (Protocol III)

\begin{tabular}{|l|l|l|}
\hline Block $A^{*}$ & Dose & Day \\
\hline Cyclophosphamide & $1500 \mathrm{mg} / \mathrm{m}^{2} / \mathrm{BS} / \mathrm{IV}$ & Day 1 \\
\hline Vincristine & $1 \mathrm{mg} / \mathrm{m}^{2} / \mathrm{BS} / \mathrm{IV}$ & Day 1 and 2 \\
\hline Rest 3 weeks & \multicolumn{2}{|l|}{} \\
\hline Bloque B & $120 \mathrm{mg} / \mathrm{m}^{2} / \mathrm{BS} / \mathrm{IV}$ & Day 1 \\
\hline Cisplatin & $100 \mathrm{mg} / \mathrm{m}^{2} / \mathrm{BS} / \mathrm{IV}$ & Day 1,2 and 3 \\
\hline Etoposide & Dose & Day \\
\hline Block C & $60 \mathrm{mg} / \mathrm{m}^{2} / \mathrm{BS} / \mathrm{IV}$ & Day 1 and 2 \\
\hline Adriamycin &
\end{tabular}

Rest 4 weeks

Total cycles: 6

Protocol according to clinical stages (Protocol IV, V, VI, VII )

\begin{tabular}{|c|c|c|c|c|}
\hline STAGE & Surgery & Chemotherapy & DAY & \begin{tabular}{|l} 
Radiotherapy \\
(Total Dose)
\end{tabular} \\
\hline I & $\begin{array}{l}\text { Complete } \\
\text { resection of } \\
\text { tumor } \\
\end{array}$ & & & \\
\hline II & \begin{tabular}{|l|} 
Complete \\
resection of \\
tumor \\
\end{tabular} & $\begin{array}{l}\text { VCR: } 1.5 \mathrm{mg} / \mathrm{m}^{2} / \mathrm{BS} / \mathrm{IV}^{*} \\
\text { CFM: } 400 \mathrm{mg} / \mathrm{m}^{2} / \mathrm{BS} / \mathrm{IV}^{*}\end{array}$ & $\begin{array}{l}1,8,29 \\
1,3,7\end{array}$ & $20 \mathrm{~Gy}^{*}$ \\
\hline III & $\begin{array}{l}1 \text { Partial } \\
\text { resection or } \\
\text { biopsy ** } \\
2 \text { Rescue }\end{array}$ & $\begin{array}{l}\text { VCR: } 1.5 \mathrm{mg} / \mathrm{m}^{2} / \mathrm{BS} / \mathrm{IV}^{* *} \\
\text { CFM:300mg/ m² } / \text { BS IV } \mathrm{IV}^{* *} \\
\text { ACTD: } 600 \mathrm{mcg} / \mathrm{m}^{2} / \text { BS } / \mathrm{IV}^{* * *} \\
\text { ADM: } 100 \mathrm{mg} / \mathrm{m}^{2} / \mathrm{BS} \mathrm{IV}^{* *}\end{array}$ & \begin{tabular}{|l}
$1,8,29$ \\
$1,3,7$ \\
$1,2,3,4$ \\
28 \\
\end{tabular} & \\
\hline & surgery ${ }^{* * *}$ & $\begin{array}{l}\text { VCR:1.5mg/ m² / BS /EV** } \\
\text { CFM:300mg/ m² / BS EV } \\
\text { DTIC:300mg/m² / BS EV } \\
\text { ADM: } 40 \mathrm{mg} / \mathrm{m}^{2} / \text { BS } / \mathrm{EV}^{* *} \\
\text { CDDP:100mg/m² } / \mathrm{BS} \mathrm{EV}^{* *}\end{array}$ & $\begin{array}{l}1,8,29 \\
2,3,4 \\
1,2,3,4 \\
8,29 \\
28 \\
\end{array}$ & $20 \mathrm{~Gy}^{*}$ \\
\hline \multirow[b]{2}{*}{ IV } & & $\begin{array}{l}\text { VCR:1.5 mg/m² / BS /EV** } \\
\text { CFM:300mg/ m²/ BS /EV } \mathrm{EV}^{* *} \\
\text { ACTD: } 600 \mathrm{mcg} / \mathrm{m}^{2} / \mathrm{BS} \mathrm{EV}^{* *} \\
\text { ADM:100mg/ m² } / \mathrm{BS} \mathrm{EV}^{* *}\end{array}$ & \begin{tabular}{|l|}
$1,8,29$ \\
$1,3,7$ \\
$1,2,3,4$ \\
28 \\
\end{tabular} & $20 \mathrm{~Gy}^{*}$ \\
\hline & Alternative & $\begin{array}{l}\text { VCR: } 1.5 \mathrm{mg} / \mathrm{m} / \mathrm{BS} / \mathrm{IV}^{* *} \\
\text { CFM:300mg/m²/BS } / \mathrm{IV}^{* *} \\
\text { DTIC:300/mg/m²/BS / IV } \\
\text { ADM: } 40 \mathrm{mg} / \mathrm{m}^{2} / \mathrm{BS} / \mathrm{IV}^{* *} \\
\text { CDDP: } 100 \mathrm{mg} / \mathrm{m}^{2} / \mathrm{BS} / \mathrm{IV}^{* *}\end{array}$ & & $20 \mathrm{~Gy}$ \\
\hline
\end{tabular}




\begin{tabular}{|l|l|l|l|l|}
\hline STAGE & Surgery & Chemotherapy & DAY & $\begin{array}{l}\text { Radiotherapy } \\
\text { (Total Dose) }\end{array}$ \\
\hline IVS & $\begin{array}{l}\text { Total resection } \\
\text { or CAFF }\end{array}$ & $\begin{array}{l}\mathrm{CFM}^{* * *} \\
\mathrm{ADM}^{* * *}\end{array}$ & $\begin{array}{l}1,2,3,4,5,6,7 \\
8\end{array}$ & \\
\hline
\end{tabular}

Abbreviations:

VCR: Vincristine

CFM: Cyclophosphamide

ACTD; Actinomycin D

ADM: Doxorubicin

DTIC: Dacarbazine

CDDP: Cisplatin

Surgery:

*In the event of existing doubts that it is a true stage I, treatment should be done with chemotherapy using the proposed outline for stage II cases.

**It is preferably recommended to carry out fine needle aspiration biopsy (FNAB) of the primary tumor

*** Surgery for biopsy specimen if there is cytoreduction of the initial tumor

Chemotherapy:

*Weekly treatment for 8 cycles, then biweekly for 8 cycles and then repeats the protocol until

completing one year of treatment.

**Rest for 3 weeks and then repeat a cycle every 3 weeks, to complete 4 cycles.

*** give a cycle every 3 weeks for 1 year.

*VCR: $1.5 \mathrm{mg}$ m2 BS IV

*CFM: 300 mg m2 BS IV

NOTE: When concluding the radiotherapy treatment, rest for 3 weeks and then continue with the initial chemotherapy protocol, 1 cycle every 4 weeks until giving 4 cycles, and later on 1 cycle every 6 weeks until giving 4 cycles, followed by 1 cycle every 8 weeks until completing 2 cycles.

\section{Radiotherapy}

For patient with low risk or neuroblastoma intermission in the plan of current treatment of COG (COG-ANBL0531), radiation therapy is reserved for patients with a symptomatic lifethreatening tumor which does not respond to chemotherapy. The treatment of children with low-risk stage $4 \mathrm{~S}$ disease depends on clinical presentation - those who are clinically stable may not require therapy. However, the disease complications, such as respiratory distress from massive hepatomegaly may need a low intensity chemotherapy regimen (low dose cyclophosphamide). Resection of the primary tumor is not associated with improved outcome.

In patients classified as intermediate risk with unfavorable biologic features, radiation therapy is given if residual viable tumor remains after 24 weeks of chemotherapy and secondlook surgery.

For patients classified as high risk, the use of radiation therapy for local control after surgical resection is recommended whether or not complete tumor removal was obtained

Schema of Hayes (Protocol VIII)

\begin{tabular}{|l|l|l|}
\hline Cyclophosphamide & $150 \mathrm{mg} / \mathrm{m}^{2} / \mathrm{BS} / \mathrm{IV}$ & Day 1 to 7 \\
\hline Adriamycin & $35 \mathrm{mg} / \mathrm{m}^{2} / \mathrm{BS} / \mathrm{IV}$ & Day 8 \\
\hline
\end{tabular}

Rest for $\{$ of $\} 3$ weeks

Total of cycles: 6 
Protocol OPEJ / OJEC (Protocol IX)

\begin{tabular}{|l|l|l|}
\hline OPEC & $1.5 \mathrm{mg} \mathrm{m}^{2} /$ BS /IV & Day 1 \\
\hline Vincristine & $80 \mathrm{mg} \mathrm{m}^{2} /$ BS/IV & Day 1 \\
\hline Cisplatin & $200 \mathrm{mg} \mathrm{m}^{2} /$ BS /IV & Day 3 \\
\hline Etoposide & $500 \mathrm{mg} \mathrm{m}^{2} /$ BS /IV & Day 1 \\
\hline Cyclophosphamide & $1.5 \mathrm{mg} \mathrm{m}^{2} /$ BS / IV & Day 1 \\
\hline OJEC & $500 \mathrm{mg} \mathrm{m}^{2} /$ BS /IV & Day 1 \\
\hline Vincristine & $200 \mathrm{mg} \mathrm{m}^{2} /$ BS /IV & Day 1 \\
\hline Carboplatin & $500 \mathrm{mg} \mathrm{m}^{2} /$ BS /IV & Day 1 \\
\hline Etoposide &
\end{tabular}

Rest for 3 weeks

Total of cycles: 7

\section{References}

[1] Carmen Gloria Rostión, Lorena Jáuregui, Valentina Broussain, Karol Gac y Angélica Paulos, Internas Mariana Hepp y Daniela Cortez. Neuroblastoma: Forma de presentación y probabilidad de resección quirúrgica. Rev. Ped. Elec. [en linea] 2005, Vol2, No2 ISSN 0718-0918

[2] Birch JM, Marsden HB. A classification scheme for childhood cancer. Int J Cancer. 1987;40:620-624.

[3] Steliarova-Foucher E, Stiller C, Lacour B, Kaatsch P. International Classification of Childhood Cancer. Third Edition. (C) 2005 American Cancer Society. DOI 10.1002/cncr.20910. Published online 14 February 2005 in Wiley InterScience (www.interscience.wiley.com).

[4] Fritz A, Percy C, Jack A, Shanmugaratnam K, Sobin Let, Parkin DM, Whelan S., editors. International Classification of Diseases for Oncology. 3rd ed. Geneva: World Health Organization, 2000.

[5] Vargas L. Cáncer infantil en Chile. 10 años. Programa PINDA. Santiago de Chile: Ministry of Health (CL); 2000

[6] Tsubono Y, Hisamichi S. A Halt to Neuroblastoma Screening in Japan (en inglés). New England Journal of Medicine. 350. 19: 2010-2011 (2004). PMID 15128908

[7] Schilling, Freimut H.; y col. (2002). «Neuroblastoma Screening at One Year of Age» N Engl J Med. Vol. 346. n. ${ }^{\circ}$ 14. pp. 1047-1053. Consultado el 4 de abril de 2009.

[8] Priscila Torres, MD, Yaima Galán, MPH, Juan Lence, MD, MPH, Mariela García, DDS, MPH, Martha Lezcano, Leticia Fernández, MD, PhD. Childhood Cancer Incidence in Cuba, 2001 to 2003. MEDICC Review, Spring 2010, Vol 12, No 2

[9] Eric Bouffet, David C. Hodgson, and ENG- SIEW KOH. Pediatric Cancers. In UICC. Prognostic Factors in Cancer. Mary K. Gospodarowicz, Brian O'Sullivan, Leslie H. Sobin. 3ed. Chapter 45. pp 317-318. 2006

[10] Lorenzo Alfonso Hernández. Oncología. Preguntas y respuestas. Instituto Nacional de Oncología y Radiobiología. Cuba. Copyright Proas Science, S. A., 2001. Provenza 388, 08025 Barcelona, España. Pp 749-754.

[11] Hiyama E, Yokohama T, Hiyama K, et al.: Multifocal neuroblastoma. Biologic behavior and surgical aspect. Cancer 2000; 88(8):1955-1963. 
[12] Shimada H, Umehara S, Monobe Y.International neuroblastoma pathology classification for prognostic evaluation of patients wishes peripheral neuroblastic tumors: a report from the Children s Cancer Group.Cancer 2001; 92:2451'61

[13] Schwab M. Amplified MYCN in human neuroblastoma-paradigm for the translation of molecular genetics to clinical oncology. Ann N Y Acad Sci 2002; 963:63-73.

[14] Neuroblastoma. Medline Plus. Enciclopedia Médica [homepage on the internet]. Maryland: US National Library of Medicine [updated 2008 Oct 6; cited 2009 Jan 29]. Available from: http://www.nim.nih.gov/medlineplus/spanish/ency/article/001408.htm

[15] Breslow N, McCann B. Statistical estimation of prognosis for children with neuroblastoma. Cancer Res 2003; 31:2092-2103.

[16] Grosfeld J.et al.: Metastasic neuroblastoma: factors influencing survival. J Pediatr Surg 2003; 13:59.

[17] Jerev B, Bretsky SS, Vogel R.Age and prognosis in neuroblastoma.Am J Pediatr Hematolo Oncol 2000; 6:233-138.

[18] Roberts S, Creamer K, Shoupe B, et al: Unique management of stage 4S neuroblastoma complicated by Massive hepatomegaly: case report and review of the literature. J Pediatr Hematol Hero B, Simon T, and Horz S, Berthold F. Metastatic neuroblastoma in infancy: what does the pattern of metastases contribute to prognosis? Med Pediatr Oncol 2000; 35:683-7

[19] Kramer K, Kushner B, et al.: Neuroblastoma metastatic.The Memorial Sloan- Kettering Cancer Center experience and a literature review.Cancer 2001; 91(8):1510-1519.

[20] Nowicki M, Miskowiak B: Prognostic value of stage IV neuroblastoma metastatic immuophenotype in the bone marrow: preliminary report. Journal of Clinical Pathology 2006;59:150-152

[21] Weinstein JL, Katzenstein HM, Cohn SL: Advances in the diagnosis and treatment of neuroblastoma. Oncologist 2003; 8(3): 278-92 Medline

[22] Anne L, Jean M, Olivier H, et al.: High-Dose chemotherapy fallowed by locoregional irradiation improves the outcome of patients with International Neuroblastoma Staging System Stage II and III Neuroblastoma with MYCN Amplification.Cancer 2004;101:1081-9

[23] Castel V, Cañete C, Melero T, et al. Results of the Cooperative Protocol(N-III-95) for metastatic relapses and refractory neuroblastoma. Med Pediatr Oncol. 2000; 35:724-26

[24] Stram DO, Matthay KK, O Leary M: Consolidation chemoradiotherapy and autologous bone marrow transplantation versus continued chemotherapy for metastasic neuroblastoma: a report of two concurrent Children s Cancer Group Studies. J Clin Oncol 2003; 13(8):2417- 2426.

[25] Howman-Giles R, Shaw PJ, Uren RF, Chung DK (2007). «Neuroblastoma and other neuroendocrine tumors» Semin Nucl Med. Vol. 37. n. ${ }^{\circ}$ 4. pp. 286-302. DOI 10.1053/j.semnuclmed.2007.02.009. PMID 17544628. 


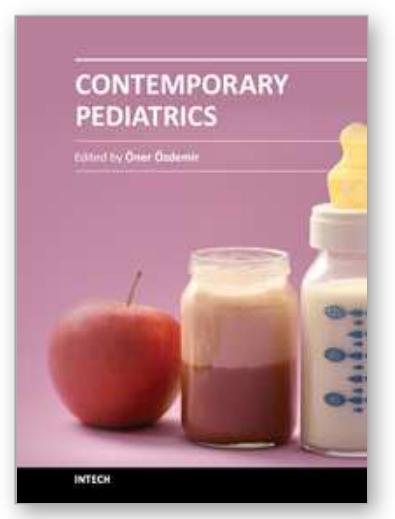

\author{
Contemporary Pediatrics \\ Edited by Dr. Öner Özdemir
}

ISBN 978-953-51-0154-3

Hard cover, 434 pages

Publisher InTech

Published online 21, March, 2012

Published in print edition March, 2012

Book Contemporary Pediatrics with its 17 chapters will help get us and patients enlightened with the new developments on the contemporary pediatric issues. In this book volume, beyond classical themes, a different approach was made to current pediatric issues and topics. This volume, as understood from its title, describes nutritional infant health and some interesting topics from pediatric subspecialties such as cardiology, hematooncology and infectious diseases.

\title{
How to reference
}

In order to correctly reference this scholarly work, feel free to copy and paste the following:

Priscila Torres Babié, Ramón de J. Ropero Toirac, Jesús de los Santos Renó and Samira Proveyer Derich (2012). Neuroblastoma - Molecular Basis for Diagnosis and Staging System, Contemporary Pediatrics, Dr. Öner Özdemir (Ed.), ISBN: 978-953-51-0154-3, InTech, Available from:

http://www.intechopen.com/books/contemporary-pediatrics/neuroblastoma-molecular-basis-for-diagnosis-andstaging-system

\section{INTECH}

open science | open minds

\section{InTech Europe}

University Campus STeP Ri

Slavka Krautzeka 83/A

51000 Rijeka, Croatia

Phone: +385 (51) 770447

Fax: +385 (51) 686166

www.intechopen.com

\section{InTech China}

Unit 405, Office Block, Hotel Equatorial Shanghai

No.65, Yan An Road (West), Shanghai, 200040, China

中国上海市延安西路65号上海国际贵都大饭店办公楼 405 单元

Phone: +86-21-62489820

Fax: +86-21-62489821 
(C) 2012 The Author(s). Licensee IntechOpen. This is an open access article distributed under the terms of the Creative Commons Attribution 3.0 License, which permits unrestricted use, distribution, and reproduction in any medium, provided the original work is properly cited. 